\title{
Enhanced Excitatory Synaptic Connectivity in Layer V Pyramidal Neurons of Chronically Injured Epileptogenic Neocortex in Rats
}

\author{
Xiaoming Jin, David A. Prince, and John R. Huguenard \\ Department of Neurology and Neurological Sciences, Stanford University School of Medicine, Stanford, California 94305
}

\begin{abstract}
Formation of new recurrent excitatory circuits after brain injuries has been hypothesized as a major factor contributing to epileptogenesis. Increases in total axonal length and the density of synaptic boutons are present in layer $\mathrm{V}$ pyramidal neurons of chronic partial isolations of rat neocortex, a model of posttraumatic epileptogenesis. To explore the functional consequences of these changes, we used laser-scanning photostimulation combined with whole-cell patch-clamp recording from neurons in layer $\mathrm{V}$ of somatosensory cortex to map changes in excitatory synaptic connectivity after injury. Coronal slices were submerged in artificial $\operatorname{CSF}\left(23^{\circ} \mathrm{C}\right)$ containing $100 \mu \mathrm{M}$ caged glutamate, APV (2-amino-5-phosphonovaleric acid), and high divalent cation concentration to block polysynaptic responses. Focal uncaging of glutamate, accomplished by switching a pulsed UV laser to give a $200-400 \mu$ s light stimulus, evoked single- or multiple-component composite EPSCs. In neurons of the partially isolated cortex, there were significant increases in the fraction of uncaging sites from which EPSCs could be evoked ("hot spots") and a decrease in the mean amplitude of individual elements in the composite EPSC. When plotted along the cortical depth, the changes in EPSCs took place mainly between 150 and $200 \mu \mathrm{m}$ above and below the somata, suggesting a specific enhancement of recurrent excitatory connectivity among layer $\mathrm{V}$ pyramidal neurons of the undercut neocortex. These changes may shift the balance within cortical circuits toward increased synaptic excitation and contribute to epileptogenesis.
\end{abstract}

Key words: epilepsy; neocortex; synaptic transmission; caged compound; electrophysiology; excitability

\section{Introduction}

Neuronal injuries after cortical trauma, stroke, and prolonged seizures result in axonal sprouting in the hippocampus and neocortex (Tauck and Nadler, 1985; Salin et al., 1995; Perez et al., 1996; Sutula et al., 1998; Esclapez et al., 1999; Golarai et al., 2001; Santhakumar et al., 2001; Buckmaster et al., 2002; Marchenko et al., 2004). This process may underlie the capacity of neuronal circuits to recover from damage (Stroemer et al., 1998; Carmichael et al., 2001; Carmichael, 2003; Lee et al., 2004); however, formation of new excitatory circuitry may also contribute to pathophysiological processes such as epileptogenesis (Purpura and Housepian, 1961; Sutula et al., 1992; Dudek and Spitz, 1997; McKinney et al., 1997; Prince et al., 1997; Prince, 1999).

Recurrent excitatory synapses formed by sprouting axons of pyramidal neurons and dentate gyrus granule cells (Perez et al., 1996; Sutula et al., 1998; Zhang et al., 1999; Wenzel et al., 2000; Buckmaster et al., 2002; Smith and Dudek, 2002) are associated

Received 0ct. 12, 2005; revised Feb. 20, 2006; accepted March 25, 2006.

This work was supported by National Institute of Neurological Disorders and Stroke Grant NS12151. This work would not have been possible without the many useful discussions with colleagues experienced with molecular uncaging approaches. We are especially thankful to Gordon M. G. Shepherd, Karel Svoboda, Kamran Khodakhah, Diana Pettit, Sam Wang, Karl Kandler, and Ed Callaway. We also thank Fran Shen for expert histological assistance. Correspondence should be addressed to John R. Huguenard, Department of Neurology and Neurological Sciences, Stanford University School of Medicine, Room M016, Stanford, CA 94305-5122. E-mail: john.huguenard@stanford.edu. D01:10.1523/JNEUROSCI.4361-05.2006

Copyright $\odot 2006$ Society for Neuroscience $\quad 0270-6474 / 06 / 264891-10 \$ 15.00 / 0$ with enhanced functional excitation in hippocampal slices from epileptic humans and rat models of temporal lobe epilepsy (Wuarin and Dudek, 1996; Patrylo and Dudek, 1998; Molnar and Nadler, 1999; Lynch and Sutula, 2000; Nadler, 2003; Scharfman et al., 2003). These injury-induced circuit reorganizations may contribute to epileptogenesis (Wuarin and Dudek, 1996, 2001; Okazaki et al., 1999) (but see Kotti et al., 1997; Longo and Mello, 1997; Sloviter, 1992).

Axonal sprouting also is present in partially isolated neocortex, a chronic model of posttraumatic epileptogenesis (Salin et al., 1995) (for review, see Graber and Prince, 2006). Increases in the total length, number of collateral branches, and the density of boutons occur in axons of layer $\mathrm{V}$ pyramidal neurons and are most prominent within layer $\mathrm{V}$, where interictal epileptiform activity is initiated (Hoffman et al., 1994). Additional experiments are required to determine whether such anatomical changes underlie functional alterations such as increases in the amplitude or frequency of spontaneous EPSCs or in the spatial extent and synchronization of excitation within cortical neuronal networks of partially isolated epileptogenic neocortex (Li and Prince, 2002; Marchenko et al., 2004).

The low "hit rate" for recording synaptically coupled layer V pyramidal cells in paired recordings, even from closely spaced neurons (Markram et al., 1997), makes such an approach unfeasible for quantitatively comparing functional connectivity across significant distances in normal versus chronically injured cortex. 
As an alternative, we used laser-scanning photostimulation of cortical slices exposed to caged glutamate, combined with wholecell patch-clamp recording (Katz and Dalva, 1994; Molnar and Nadler, 1999; Dantzker and Callaway, 2000; Shepherd et al., 2003) to map and quantify changes in monosynaptic excitatory connectivity. The strength and distribution of synaptic inputs from cortical layers II-VI onto layer V pyramidal neurons in slices from control and partially isolated cortex were compared. Data indicate that there is an increase in the efficacy and extent of recurrent excitatory synaptic connectivity among layer $\mathrm{V}$ pyramidal neurons of the undercut neocortex. Portions of these results have been published in abstract form (Jin et al., 2005b).

\section{Materials and Methods}

Surgical procedures. All experiments were performed according to protocols approved by the Stanford Institutional Animal Care and Use Committee. Neocortical slices from 28 Sprague Dawley rats aged postnatal day 35 (P35) to $\mathrm{P} 41$ ( $\mathrm{P} 0$, date of birth) were used for in vitro recordings. Partially isolated islands of neocortex ("undercuts") were produced in 11 anesthetized rats at P21, using previously described techniques (Hoffman et al., 1994; Li and Prince, 2002). Rats were deeply anesthetized with ketamine $(80 \mathrm{mg} / \mathrm{kg}$, i.p.) and xylazine (Rompun, $8 \mathrm{mg} / \mathrm{kg}$, i.p.), mounted in a stereotaxic frame, the scalp incised and retracted, and a portion of frontoparietal cortex of the left hemisphere exposed by removing a $\sim 3 \times 5 \mathrm{~mm}$ bone window centered on the coronal suture, leaving the dura intact. A partial isolation of an island of sensorimotor cortex was made as described previously. A 30 gauge needle, bent at approximately a right angle $2.5-3 \mathrm{~mm}$ from the tip, was inserted tangentially through the dura, just beneath the pial vessels, parasagittally $1-2$ $\mathrm{mm}$ from the interhemispheric sulcus, and lowered to a depth of $2 \mathrm{~mm}$. The needle then was rotated $120-135^{\circ}$ to produce a contiguous white matter lesion, elevated to a position just beneath the pia, and removed. The skull opening was then covered with sterile plastic wrap (Saran Wrap), and the skin was sutured. Rats were allowed to recover for at least 2 weeks, a latency at which most in vitro slices containing a portion of the injured area generated evoked epileptiform activity in previous experiments (Hoffman et al., 1994; Graber and Prince, 1999)

Slice preparation and recording. Animals were anesthetized with pentobarbital (55 mg/kg, i.p.) and decapitated, and the brain was rapidly removed and placed in ice-cold $\left(4^{\circ} \mathrm{C}\right)$ oxygenated slicing solution containing the following (in mM): 230 sucrose, $2.5 \mathrm{KCl}, 1.25 \mathrm{NaH}_{2} \mathrm{PO}_{4}, 10$ $\mathrm{MgSO}_{4} \cdot 7 \mathrm{HO}_{2}, 10$ glucose, $0.5 \mathrm{CaCl}_{2} \cdot 2 \mathrm{H}_{2} \mathrm{O}$, and $26 \mathrm{NaHCO}_{3}$. The area of the cortical lesion was easily identified in the left hemisphere. Coronal slices $(300 \mu \mathrm{m})$ were cut with a vibratome (Lancer Series 1000; Vibratome Company, St. Louis, MO) through the lesioned sensorimotor cortex and from the same region in control animals, and maintained using standard techniques (Li and Prince, 2002). After $\sim 1 \mathrm{~h}$ incubation at $36^{\circ} \mathrm{C}$ in standard artificial CSF (ACSF), slices were held at room temperature. The ACSF contained the following (in $\mathrm{mm}$ ): $126 \mathrm{NaCl}, 2.5 \mathrm{KCl}$, $1.25 \mathrm{NaH}_{2} \mathrm{PO}_{4}, 2 \mathrm{CaCl}_{2} \cdot 2 \mathrm{H}_{2} \mathrm{O}, 2 \mathrm{MgSO}_{4} \cdot 7 \mathrm{H}_{2} \mathrm{O}, 26 \mathrm{NaHCO}_{3}$, and 10 glucose, $\mathrm{pH} 7.4$ when saturated with $95 \% \mathrm{O}_{2}-5 \% \mathrm{CO}_{2}$.

Patch electrodes were pulled from borosilicate glass tubing (outer diameter, $1.5 \mathrm{~mm}$ ) and had an impedance of 4-7 $\mathrm{M} \Omega$ when filled with intracellular voltage-clamp solution containing the following (in $\mathrm{mM}$ ): 120 Cs-gluconate, $10 \mathrm{KCl}, 11 \mathrm{EGTA}, 1 \mathrm{CaCl}_{2} \cdot 2 \mathrm{H}_{2} \mathrm{O}, 2 \mathrm{MgCl}_{2} \cdot 6 \mathrm{H}_{2} \mathrm{O}, 10$ HEPES, $2 \mathrm{Na}_{2} \mathrm{ATP}, 0.5 \mathrm{NaGTP}$, and $0.5 \%$ biocytin. In current-clamp experiments, we used a K-gluconate-based intracellular solution containing the following (in $\mathrm{mm}$ ): $95 \mathrm{~K}$-gluconate, $40 \mathrm{KCl}, 5$ EGTA, 0.2 $\mathrm{CaCl}_{2} \cdot 2 \mathrm{H}_{2} \mathrm{O}, 10 \mathrm{HEPES}$, and $0.5 \%$ biocytin. The osmolarity of the pipette solutions was adjusted to 285-295 mOsm and $\mathrm{pH}$ to 7.3 with $1 \mathrm{M}$ $\mathrm{KOH}$. Single slices were transferred to a recording chamber where they were minimally submerged in high divalent ACSF that contained the following (in mM): $121 \mathrm{NaCl}, 2.5 \mathrm{KCl}, 1.25 \mathrm{NaH}_{2} \mathrm{PO}_{4}, 4 \mathrm{CaCl}_{2}, 4$ $\mathrm{MgSO}_{4} \cdot 7 \mathrm{H}_{2} \mathrm{O}, 26 \mathrm{NaHCO}_{3}$, and 10 glucose. Patch-clamp recordings were made from visually identified layer $\mathrm{V}$ pyramidal cells in undercut cortex or the same region in control slices, using infrared video microscopy (Zeiss Axioskop; Carl Zeiss, Oberkochen, Germany) and a $63 \times$ water-immersion lens (Achroplan 63×, 0.9 W; Carl Zeiss) with differen- tial interference contrast optics and an Axopatch 200A amplifier (Molecular Devices, Foster City, CA). Access resistance was measured in voltage-clamp mode from responses to $5 \mathrm{mV}$ depolarizing voltage pulses. Recordings with access resistance $<30 \mathrm{M} \Omega$ and without significant changes $(<25 \%)$ during the recording were used for data analysis. The responses were low-pass filtered at $2 \mathrm{kHz}$ and recorded on hard disk for later analysis. EPSCs were measured at a holding potential of $-70 \mathrm{mV}$, close to reversal for fast inhibition.

Polysynaptic recurrent excitation (Prince and Tseng, 1993; Lynch and Sutula, 2000) is common in different models of epileptogenesis, which raises the concern that polysynaptic activity could be evoked by glutamate uncaging and result in incorrect maps of excitatory synaptic input. To address this issue, we used a high-divalent ACSF containing $4 \mathrm{~mm}$ $\mathrm{Ca}^{2+}, 4 \mathrm{mM} \mathrm{Mg}^{2+}$ (Shepherd et al., 2003), and $10 \mu \mathrm{M}$ 2-amino-5phosphonovaleric acid (APV) to eliminate potential polysynaptic activation via NMDA receptors. We tested the effectiveness of this solution in blocking polysynaptic activity under conditions of reduced inhibition. When the control slices were perfused in normal ACSF containing $10 \mu \mathrm{M}$ $\mathrm{GABA}_{\mathrm{A}}$ receptor antagonist bicuculline, polysynaptic events occurred spontaneously. These polysynaptic events were completely abolished when the perfusate was switched to one containing $10 \mu \mathrm{m}$ bicuculline, 10 $\mu \mathrm{M} \mathrm{APV}$, and the increased divalent cation concentrations (see above) (data not shown), suggesting that this perfusion solution was effective in reducing polysynaptic transmission. Furthermore, examination of action potential (AP) firing evoked by photostimulation revealed that, whereas direct uncaging stimuli clearly could evoke one or more APs, no such firing was induced by evoked or spontaneous EPSPs in either control and undercut slices. These control data ruled out the possibility of polysynaptic activation from photostimulated neurons under our recording conditions. Addition of $10 \mu \mathrm{M}$ APV also eliminated NMDAmediated long-lasting plateau potentials (Wei et al., 2001), which could otherwise interfere with the detection of individual AMPA receptormediated synaptic events.

After the electrophysiological recordings, slices containing biocytinfilled neurons were fixed and processed with the standard avidin-biotin peroxidase method (Horikawa and Armstrong, 1988; Tseng et al., 1991) or immunofluorescent staining. Labeled neurons were examined under light or confocal microscopy to verify their morphology and location.

Photolysis of caged glutamate and stimulus patterns. An uncaging setup was built according to the principles described by Tsai et al. (2002) (see also Shepherd and Svoboda, 2005). An upright microscope (Axioskop) with a fixed stage and submersion slice chamber was mounted on a locally made mobile stage that allowed coincident longitudinal displacement of the microscope and the laser unit relative to the slice. The slice was imaged with a monochrome charge-coupled device $(\mathrm{CCD})$ video camera (Cohu, San Diego, CA). A frequency-tripled Nd: $\mathrm{YVO}_{4}$ laser (Series 3500 pulsed laser; $100 \mathrm{kHz}$ repetition rate; DPSS Lasers, San Jose, CA) was used to provide $50-100 \mathrm{~mW}$ of $355 \mathrm{~nm}$ light. The UV laser was coupled to the epifluorescence port of the microscope through several mirrors and a lens assembly that focused the light with 1:2 amplification onto a dichroic mirror, reflecting the light beam to the back aperture of a $5 \times$ objective (Fluar $5 \times$; Carl Zeiss). The movement of the laser beam was precisely controlled with mirror galvanometers (model 6210; Cambridge Technology, Cambridge, MA), trigged by scanning and data acquisition software developed by J. R. Huguenard.

A concentration of $100 \mu \mathrm{M}$ caged glutamate (methyl 1-[5-(4-amino4-carboxybutanoyl)]-7-nitroindoline-5-acetate) and $10 \mu \mathrm{M} \mathrm{APV} \mathrm{(both}$ from Sigma, St. Louis, MO) were added to $20 \mathrm{ml}$ of recirculating high divalent ACSF at the beginning of experiments. Once a whole-cell recording was established, the lens was switched to the $5 \times$ objective. Focal photolysis of caged glutamate was accomplished by switching the UV laser to give a $200-400 \mu$ s light stimulus. The mapping stimulus patterns consisted of 264 positions on an $11 \times 25$ grid. Spacing between adjacent rows and columns was set to $50 \mu \mathrm{m}$, resulting in a $500 \times 1200 \mu \mathrm{m}$ mapping area in the slices. The grid was carefully aligned to cover cortical layers II-VI. When a single map did not cover all cortical layers, two shorter grids of $500 \mu \mathrm{m}$ wide were used to extend over the lower and upper half of the cortex separately. We used a random stimulus sequence pattern at a $1 \mathrm{~s}$ interstimulus interval. Each recorded trace consisted of a 
$100 \mathrm{~ms}$ prestimulus baseline and a $500 \mathrm{~ms}$ poststimulus period. We repeatedly recorded evoked responses from a few individual uncaging spots with 5-20 s interstimulus interval, and found that direct and synaptic responses from a single uncaging spot were quite consistent and reproducible $(n=4)$. In most mapping experiments, repeated photostimulation of the same cortical regions resulted in comparable maps of synaptic input with small variation.

Data acquisition and analysis. Responses evoked by glutamate uncaging were analyzed within a time window between $12 \mathrm{~ms}$ and $200 \mathrm{~ms}$ after photostimulation. This time window was chosen because all excitatory responses attributable to direct effects of uncaged glutamate on the recorded neuron peaked within $12 \mathrm{~ms}$ after photostimulation (see Fig. 1C) and thus could be separated from the later occurring synaptic responses. All directly evoked APs occurred within a window between 12 and $200 \mathrm{~ms}$ after the onset of photostimulation, and most of them fell within the first $100 \mathrm{~ms}$. These differences in latency allowed us to include all evoked synaptic responses in the data analysis. EPSCs evoked by uncaging were analyzed using PSC detection software, Wdetecta (Ulrich and Huguenard, 1996) (http://huguenardlab.stanford.edu/apps/wdetecta/). The detector parameters, including differentiation window size and event amplitude, were carefully adjusted and tested for recorded traces of each map to ensure correct detection of synaptic events. Once proper settings were determined, the program automatically and accurately detected synaptic events and generated a number of quantitative parameters of the evoked EPSCs.

We used three measures of detected EPSCs to quantify the characteristics of synaptic connectivity. For spots that evoked EPSCs, the "composite EPSC amplitude" was defined as the sum of the amplitudes of all detected synaptic events during the $200 \mathrm{~ms}$ time window in each recording trace (see Fig. $1 G$, amplitude of $\mathrm{b}+\mathrm{c}$ ). The "EPSC number" refers to the total number of events in a response (see two events in Fig. $1 G$ ). The "mean individual EPSC amplitude" was obtained by dividing composite EPSC amplitude by EPSC number [see Fig. $1 G,(b+c) / 2$ ]. As an indicator of the extent of synaptic connectivity, composite amplitude for each spot of photostimulation was used to construct maps of synaptic inputs for individual neurons (see Fig. 4B,C).

We used a modified Sholl analysis to compare the intensity of synaptic inputs between the control and undercut groups. This involved calculating the EPSC amplitude for each cell evoked by uncaging stimuli delivered within concentric $100 \mu \mathrm{m}$ rings centered on its soma (see Fig. 4D). The "region-normalized EPSC amplitude" was obtained by dividing the sum of all composite EPSC amplitudes evoked within a given circular Sholl region by the total number of stimulus sites within the region (see Fig. $4 E, F$ ). This holistic measure reflects strength of functional synaptic coupling within a region and incorporates both number and amplitude of evoked events. "Hot spots" were defined as sites on the stimulation grid from which a synaptic event could be evoked. To compare the size of the synaptic input maps, the number of hot spots within a given Sholl circular area was divided by the total number of stimulated sites within the same area to give "fractional hot spots" (see Fig. 4G,H). Analysis of region-normalized EPSC amplitude and fractional hot spots along vertical and horizontal axes revealed possible changes in interlaminar and intralaminar connectivity, respectively. The mean EPSC number, composite EPSC amplitude, and individual EPSC amplitude were also analyzed using the modified Sholl method by separately dividing the sum of EPSC number, composite EPSC amplitude, and individual EPSC amplitude in a given circular Sholl area by the number of hot spots in the same Sholl region.

Statistical significance for group means was determined with twotailed Student's $t$ test with $p<0.05$. Results from modified Sholl analyses were analyzed by two-way ANOVAs. Additional comparisons between control and undercut groups at each individual distance from the soma were made with Student's $t$ test (Kittelberger and Mooney, 1999). Data are presented as mean \pm SEM. Origin and Microsoft Excel software were used to perform all statistical analyses.

\section{Results}

Coronal brain slices were prepared from control and undercut rats aged P35-P41, 14-20 d after partial isolations in lesioned animals. Transcortical cuts were easily seen in slices under a lowpower objective. Undercutting lesions were present in white matter closely adjacent to layer VI, and a small area of cavitation was often associated with the undercut. Cortical pyramidal neurons were visually identified based on their location, pyramidalshaped somata, and a single emerging apical dendrite extending toward the pial surface. Their pyramidal cell identities were later confirmed by morphological images from biocytin staining (see Fig. 3). Maps of uncaging-evoked synaptic events were obtained from pyramidal neurons of layers $\mathrm{Va}$ and $\mathrm{Vb}$ within the partially isolated cortex and from homologous areas of control cortex from age-matched untreated rats, whereas recordings of evoked AP firing in current clamp were from layers II-VI of the control and undercut cortex. Based on their dendritic morphology and our previous results (Jin et al., 2005a), layer V pyramidal neurons included both regular spiking neurons and intrinsically burst firing neurons. It is known that excitatory synaptic input onto these two type of pyramidal neurons are different in layers II/III, IV, and VI (Schubert et al., 2001). Because axonal sprouting in undercut rats occurs mainly in layer V (Salin et al., 1995), we did not differentiate data from these two groups of cells for analysis.

\section{Spatial resolution of photostimulation}

To test the spatial resolution and determine the timing of direct neuronal activation, we applied uncaging stimuli to $350 \times 350$ $\mu \mathrm{m}$ regions at $50 \mu \mathrm{m}$ intervals under voltage clamp in control brain slices, perfused with ACSF containing $1 \mu \mathrm{M}$ TTX and $10 \mu \mathrm{M}$ APV to block synaptic activity and NMDA receptor-mediated responses. Under these conditions, direct activation of nonNMDA glutamate receptors was mapped for individual neurons (Fig. 1 $A, B$ ). All direct responses initiated with little or no delay from the onset of the uncaging stimulus and peaked within $8-12$ $\mathrm{ms}$ (Fig. 1C). The maximal direct activation resulted from glutamate uncaging was in the perisomatic area, with one or two spots eliciting the largest response (Fig. $1 B$ ). This result indicates that spatial resolution of direct activation was $<50 \mu \mathrm{m}$ and that response onset after direct activation (Fig. 1C) was similar to values described in previous reports (Schubert et al., 2001; Shepherd et al., 2003). These findings allowed us to separate synaptic responses from those attributable to direct activation by detecting events with latencies 10-12 ms after uncaging in mapping experiments (Fig. 1D-G).

Our previous results showed that layer $\mathrm{V}$ pyramidal neurons in the partial cortical isolation have increased input resistance and membrane time constant (Jin et al., 2005a; Prince and Tseng, 1993), as well as a steeper relationship between AP frequency and depolarizing current (Prince and Tseng, 1993) (see also Tseng and Prince, 1996). Such changes in intrinsic properties might result in enhanced excitability and increased AP firing when neurons are depolarized by uncaged glutamate. To rule out this possibility and further determine the spatial resolution of photostimulation in undercut and control cortical slices, we obtained whole-cell and loose-seal recordings from pyramidal neurons in cortical layers II $\sim$ VI in current-clamp mode to generate maps of evoked AP firing. Neurons were photostimulated in an area of $500 \times 500 \mu \mathrm{m}$ with $40 \mu \mathrm{m}$ spacing and a laser flash duration of 200-400 $\mu$ s. All neurons recorded fired APs when stimuli were located close to the soma or apical or basal dendrites (Fig. 2A,B). When the duration of laser uncaging was substantially increased to $400 \sim 800 \mu$ s, evoked APs appeared with stimuli at greater distances from somata (data not shown). There were no significant differences between the control $(n=19)$ and undercut $(n=$ 16) groups of cells in total spike number per neuron (5.5 \pm 0.9 in 
control; $5.8 \pm 0.8$ in undercut), mean number of AP-generating spots per neuron $(2.8 \pm 0.3$ in control; $3.6 \pm 0.3$ in undercut), and number of APs per spot $(2.0 \pm 0.2$ and $1.7 \pm 0.3$ in control and undercut groups, respectively) (Fig. 2C). Therefore, under our experimental conditions, there was no significant increase in excitability of pyramidal neurons in the undercut cortex that would affect responses of presynaptic cells to glutamate uncaging, and maps of synaptic input generated by photostimulation. In all cortical layers, all APs occurred with stimuli within an effective radius of $<100 \mu \mathrm{m}$ from somata (mean, $80.3 \pm 6.8 \mu \mathrm{m}$ in control and $87.5 \pm 5.9 \mu \mathrm{m}$ in undercut; $p>0.05)$. There were also no significant differences in mean effective radius between the control and undercut groups in layer $\mathrm{V}$ pyramidal neurons and in pyramidal neurons of other cortical layers (Fig. 2D). The above result suggests that most pyramidal neurons in a slice can be depolarized to threshold for firing APs in response to glutamate uncaging with a spatial resolution close to $100 \mu \mathrm{m}$, confirming that we were able to generate synaptic input maps with sublaminar resolution.

\section{Increased excitatory connectivity in partially isolated cortex}

We previously found significant increases in axonal length, collaterals, and synaptic bouton density in layer $\mathrm{V}$ pyramidal neurons of the undercut cortex (Salin et al., 1995) as well as increases in the frequency and amplitude of spontaneous EPSCs (sEPSCs) and frequency of miniature EPSCs (Li and Prince, 2002), supporting the hypothesis that formation of new recurrent synaptic connections contributes to the enhancement of excitatory synaptic connectivity. To further test this hypothesis, we used the laser-scanning photostimulation technique to detect changes in monosynaptic excitatory connectivity in layer $\mathrm{V}$ pyramidal neurons.

Whole-cell voltage-clamp recordings were obtained from 18 control and 17 undercut neurons that were filled with biocytin and retrospectively identified as layer $\mathrm{V}$ pyramidal cells (Fig. 3). To evaluate the frequency and amplitude of spontaneous EPSCs in our experiment condition, we recorded sEPSCs for 2-3 $\mathrm{min}$ in voltageclamp mode at $-70 \mathrm{mV}$ at the beginning of each experiment. The mean sEPSC frequency averaged from cells of the undercut group $(3.2 \pm 0.7 \mathrm{~Hz} ; n=17)$ was slightly higher than that in the control group $(2.7 \pm 0.3 \mathrm{~Hz} ; n=18)$, but the difference was not statistically significant ( $p>0.05$, Student's $t$ test), ruling out the possibility of sEPSC making significant contribution to the

A

C

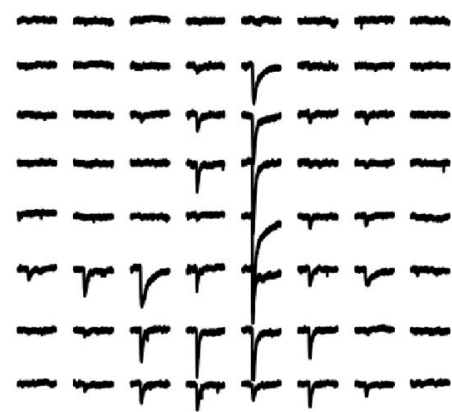

B
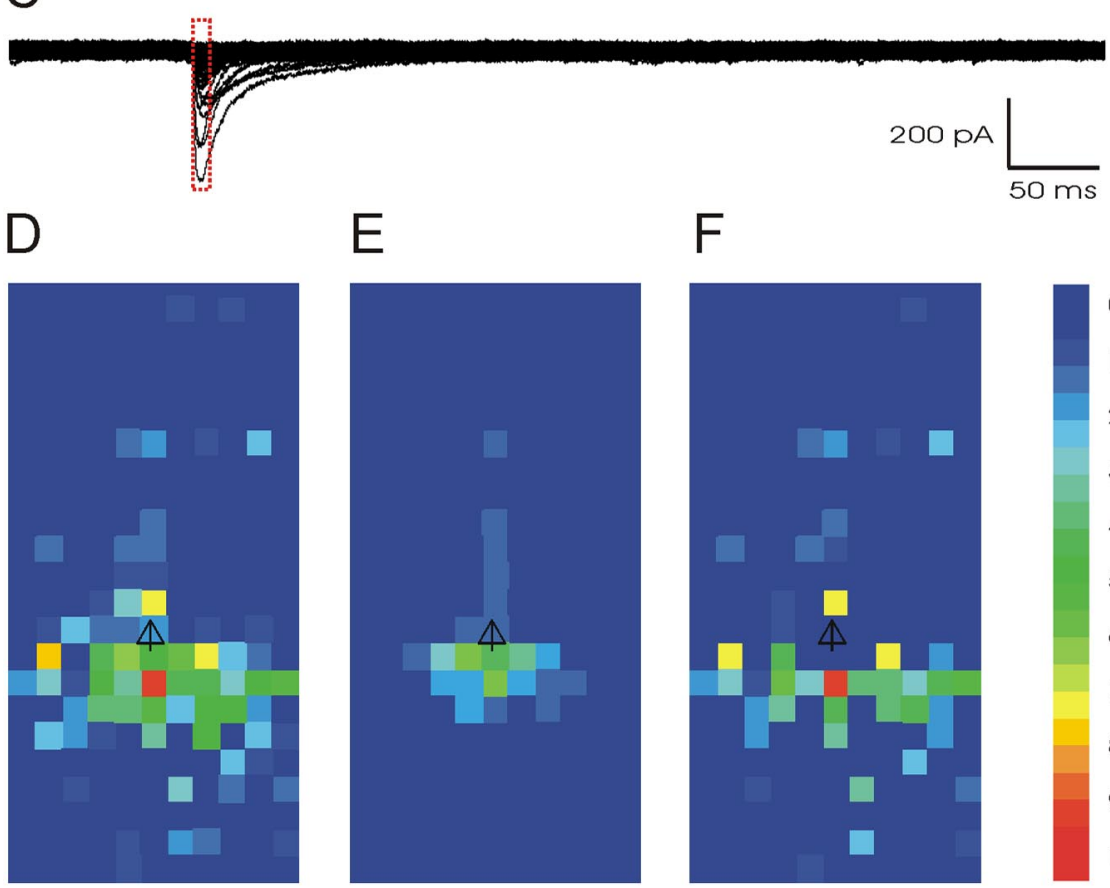

F

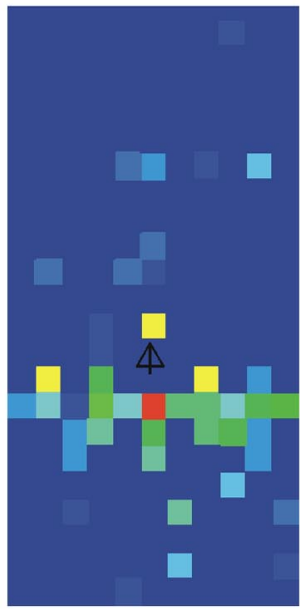

0

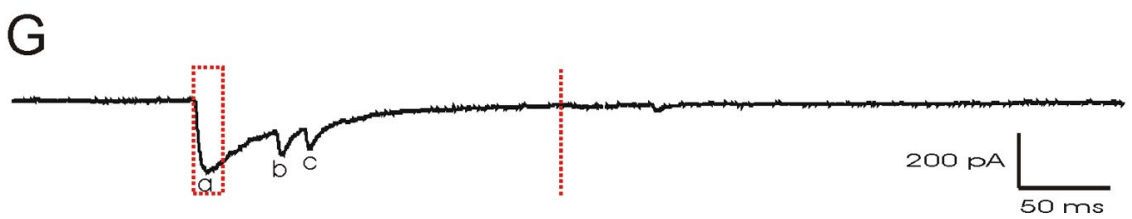

Figure 1. Spatial resolution of photostimulation and generation of excitatory synapticinput maps. $A-C$, Direct activation profile under voltage-clamp recording of a layer V pyramidal neuron in ACSF containing TX and APV (see Materials and Methods). $\boldsymbol{A}$, Responses of a layer V pyramidal neuron generated by photostimulation in a $400 \times 400 \mu \mathrm{m}$ square area with $50 \mu \mathrm{m}$ spacing. Superimposed responses shown in $\boldsymbol{C}$, , Map generated from peak amplitudes of direct responses in $\boldsymbol{A}$. Response intensity, in picoamperes, is color coded according to the scale on the right. $\boldsymbol{B}, \boldsymbol{D}-\boldsymbol{F}$, Triangle, Site of somata. $\boldsymbol{C}$, Direct responses evoked by glutamate in cell of $\boldsymbol{A}$ and $\boldsymbol{B}$. Responses peaked within the first $10 \mathrm{~ms}$ after the laser stimulus (red rectangular area). $\mathbf{D}-\mathbf{G}$, Responses from another pyramidal neuron to laser uncaging of glutamate. $\boldsymbol{D}$, Color-coded map of composite amplitude of both direct and synaptic responses evoked by glutamate uncaging (see Materials and Methods) at a holding potential of $-70 \mathrm{mV}$ in a bathing solution containing $4 \mathrm{~mm} \mathrm{Ca}^{2+} / 4 \mathrm{~mm} \mathrm{Mg}^{2+}$.E, Map of direct activation responses constructed by detecting peak events within $10 \mathrm{~ms}$ of glutamate uncaging. The direct activation profile coincided with the presumed position of the portion of the dendritic tree of this pyramidal neuron. $F, A$ synaptic map of the neuron of $D-G$, generated by excluding direct activation responses of $\boldsymbol{E}$ (i.e., those before $10 \mathrm{~ms}$ ) from the total responses of $\boldsymbol{D}$. Grid spacing is $50 \mu \mathrm{m}$ for $\boldsymbol{D}-\boldsymbol{F}$. Scale on right, Composite amplitude of trigged events (in picoamperes). G, A representative trace containing both direct and synaptic responses. Direct response (a) to photostimulation occurred within the first $10 \mathrm{~ms}$ (red rectangle), synaptic responses $(b, c)$ were detected within the first $200 \mathrm{~ms}$ (between the end of the red rectangle and the dashed red line) after photostimulation.

change in synaptic input maps in undercut neurons. In contrast, the amplitude of sEPSC in the undercut group was smaller than the control $(-11.0 \pm 0.9 \mathrm{pA}$ in undercut vs $-14.3 \pm 1.1 \mathrm{pA}$ in control; $p<0.05$, Student's $t$ test). This latter difference would 

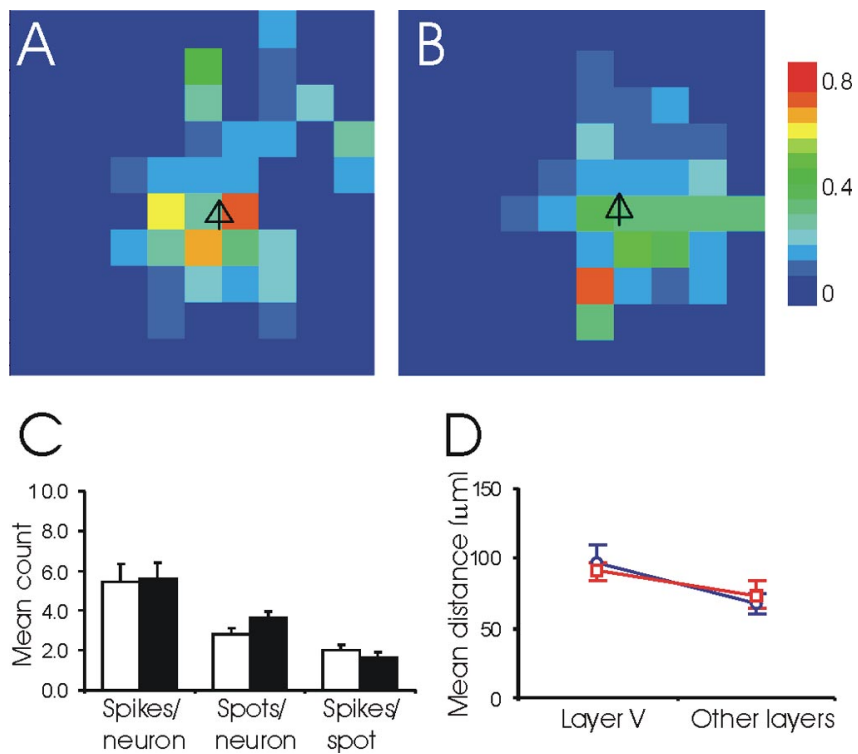

Figure 2. Direct excitation profiles of pyramidal neurons in control and undercut cortex. $\boldsymbol{A}, \boldsymbol{B}$ The $500 \times 500 \mu \mathrm{m}$ grids were photostimulated by laser spots with a $40 \mu \mathrm{m}$ spacing, and the average number of evoked action potentials evoked by each spot was plotted in 19 control $(\boldsymbol{A})$ and 16 undercut neurons $(\boldsymbol{B})$. Most of the APs were activated by stimuli close to the somata (triangles) of the recorded neurons. Scale to the right, Average number of APs evoked by spots. $\boldsymbol{C}, \boldsymbol{D}$, Analysis of direct excitation profiles. $\boldsymbol{C}$, There were no significant differences between the control (open bars; $n=19$ ) and undercut (black bars; $n=16$ ) in the average total number of APs per neuron (left graph), average active spots per neuron (middle), or number of spikes per spot (right). $\boldsymbol{D}$, There were also no significant differences in the mean distance from the soma of all of the spots that could evoke action potentials (effective radius) between the control and undercut groups in layer $V$ pyramidal neurons and in pyramidal neurons in other cortical layers (layers II IV and Vl; $p>0.05$, one-way ANOVA). The mean effective radius was larger in layer $V$ pyramidal neurons than in pyramidal neurons of other layers, but no significant differences were observed between control and undercut groups in either layer $(p>0.05$, one-way ANOVA). Blue open circles, Control; red squares, undercut. Error bars indicate SEM.
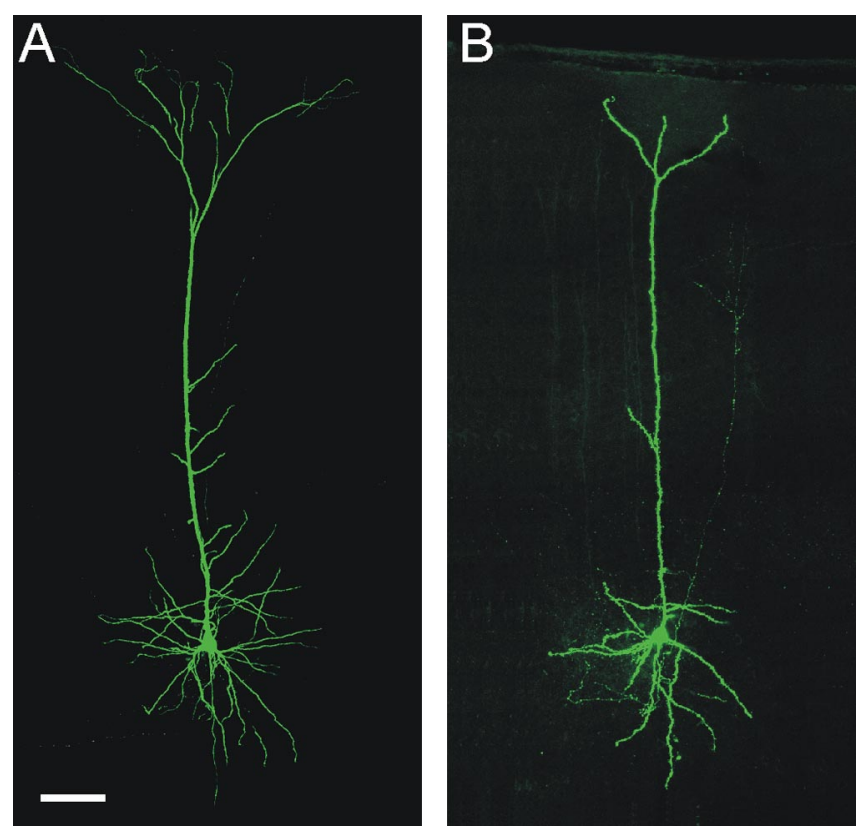

Figure 3. Confocal images of biocytin-filled layer V pyramidal neurons in control $(\boldsymbol{A})$ and undercut $(\boldsymbol{B})$ 300- $\mu \mathrm{m}$-thick coronal neocortical slices. FITC was conjugated to the biocytin reaction product to produce green fluorescence. Both control and undercut neurons had large somata and a thick primary apical dendrite, characteristic of deep-lying layer V pyramidal cells. Scale bar: (in $A$ for both neurons) $100 \mu \mathrm{m}$. tend to decrease the contamination of synaptic maps that might result from spontaneous activity. Thus, the increases in connectivity reported below are unlikely to result from either differences in intrinsic excitability or spontaneous synaptic activity between control and undercut cortex.

For each recorded neuron, focal photolysis of caged glutamate was used to stimulate a single $\sim 0.5 \times 1.2 \mathrm{~mm}$ region or two shorter regions of $0.5 \mathrm{~mm}$ wide to cover cortical layers II-VI with a grid spacing of $50 \mu \mathrm{m}$. We constructed maps of excitatory synaptic input to individual pyramidal neurons and compared input strength across cortical layers based on the composite EPSC amplitude evoked by uncaging at each spot and the fraction of hot spots at which EPSCs could be evoked. Most excitatory input onto layer $\mathrm{V}$ pyramidal neurons was from a region within $300 \mu \mathrm{m}$ of the soma, within the extent of layer $\mathrm{V}$; inputs from other laminas contributed to a less degree (Figs. 4, 5). Within the partial isolation, the intensity of excitatory synaptic input from sites within $\sim 300 \mu \mathrm{m}$ of somata was increased, as measured by the region-normalized EPSC amplitude of evoked events (Fig. 5A) and by the fraction of hot spots within the same area (Figs. 4G, $H$, $5 B$ ). These changes were not always prominent in individual neurons (Fig. $4 E, F$ ) but were significant in the population of pyramidal cells examined.

A modified Sholl analysis (see Materials and Methods) (Fig. $4 D)$ showed significant increases in region-normalized EPSC amplitude ( $F=9.0 ; p=0.003$, two-way ANOVA) (Fig. 5A) and in the fraction of hot spots $(F=28.0 ; p<0.0001$, two-way ANOVA) (Fig. 5B) evoked by stimuli between the control and undercut groups. Additional analysis indicated that the increases in region-normalized EPSC amplitude occurred within the area of circular bands that extended out 100, 200, and $300 \mu \mathrm{m}$ from somata. The region-normalized EPSC amplitude evoked from these circular areas was $-11.5 \pm 2.3 \mathrm{pA}(0-100 \mu \mathrm{m}),-8.9 \pm 1.8$ pA $(100-200 \mu \mathrm{m})$, and $-6.5 \pm 1.6 \mathrm{pA}(200-300 \mu \mathrm{m})$ in the control, and $-22.5 \pm 3.1 \mathrm{pA},-18.3 \pm 2.2 \mathrm{pA}$, and $-11.5 \pm 1.7$ $\mathrm{pA}$ within comparable areas in the undercut group $(p<0.05 \sim$ $p<0.005$, Student's $t$ test) (Fig. $5 A$ ). There were significant increases in the fraction of hot spots within the circular bands close to somata (mean fraction of hot spots was $0.37 \pm 0.05,0.35 \pm$ 0.05 , and $0.31 \pm 0.05$ in the control, and $0.58 \pm 0.05,0.59 \pm 0.05$, and $0.50 \pm 0.06$ in the undercut group for bands $0-100 \mu \mathrm{m}$, 100-200 $\mu \mathrm{m}$, and 200-300 $\mu \mathrm{m}$, respectively $(p<0.05 \sim p<$ 0.005 , Student's $t$ test) (Fig. $5 B$ ). There were also significant, but less marked, increases in region-normalized EPSC amplitude and mean fraction of hot spots/total sites stimulated in bands of undercut cortex more distant from somata (Fig. $5 A, B$ ).

The analysis of evoked EPSCs was complicated by the observation that multiple EPSCs were evoked from most stimulated spots. To determine the factors that contribute to changes in the region-normalized EPSC amplitude, we further analyzed the mean EPSC number and the mean composite EPSC amplitudes in modified Sholl analysis. Two-way ANOVA analysis indicated a significant difference in the mean EPSC number per hot spot between the control and undercut groups $(F=28.2 ; p<0.0001)$. There were modest but significant increases in the mean EPSC number per hot spot in two Sholl regions, between 100-200 $\mu \mathrm{m}$ and 500-600 $\mu \mathrm{m}$ of somata (data not shown), and the overall (across all regions) mean EPSC number per hot spot increased significantly in the undercut versus control group (mean EPSC number, $1.48 \pm 0.04$ in undercut, $1.32 \pm 0.03$ in control; $p<$ 0.0005 , Student's $t$ test). No significant difference in the mean composite EPSC amplitude was found between the control and undercut groups either in the general group mean or in mean 
amplitude within each Sholl area (data not shown). The mean individual EPSC amplitude was significantly smaller in the undercut group $(-16.5 \pm 0.3$ vs $-12.5 \pm 0.6$ $\mathrm{pA}$ in the control and undercut groups, respectively; $p<0.001$, Student's $t$ test), consistent with result from sEPSC recording (see above). The cumulative probability plot of individual EPSC amplitudes from control and undercut neurons (Fig. 5C) showed a significant left shift for undercut neurons [Kolmogorov-Smirnov (K-S) test, $p<0.0001]$, confirming the mean individual amplitude result. Mean individual EPSC amplitudes were generally smaller in all Sholl regions, but significant differences between the two groups were only observed at distances of $400-$ $500 \mu \mathrm{m}(-17.1 \pm 1.2 \mathrm{pA}$ in control vs $-12.3 \pm 0.9 \mathrm{pA}$ in undercut; $p<0.005)$ and $800-900 \mu \mathrm{m}(-16.5 \pm 2.3 \mathrm{pA}$ control and $-11.0 \pm 0.6 \mathrm{pA}$ undercut; $p<0.05)$ (data not shown).

To determine alterations in the laminar source of the excitatory synaptic input, we further analyzed the changes in regionnormalized EPSC amplitude and fraction of hot spots relative to the cortical depth of the uncaging stimulus. There were significant differences between the control and undercut group in region-normalized EPSC amplitude and mean fraction of hot spots $(F=40.1, p<0.0001$; and $F=61.1$, $p<0.0001$, respectively; two-way ANOVA) (Fig. 6A, B). Consistent with the above modified Sholl analysis (Fig. 5) and results of previous experiments on the distribution of axonal sprouting in the partially isolated cortex (Salin et al., 1995), the most significant increases in regionnormalized EPSC amplitude and mean fraction of hot spots were centered in an area between $175 \mu \mathrm{m}$ below and $125 \mu \mathrm{m}$ above the somata of pyramidal neurons in layer $\mathrm{V}$ of the undercut cortex $(p<0.05 \sim$ $p<0.005$, Student's $t$ test) (Fig. 6A,B). There were also significant increases in region-normalized EPSC amplitude in areas $375 \mu \mathrm{m}(p<0.05)$ and $725 \mu \mathrm{m}(p<$ 0.01 ) superficial to the somata in layer $V$, and significant increases in mean fraction of hot spots at four depths between $\sim 375$ and $875 \mu \mathrm{m}(p<0.05 \sim 0.005)$ (Fig. $6 B)$. The data suggest that, compared with control, layer $\mathrm{V}$ pyramidal neurons in the undercut cortex receive more widespread excitatory synaptic input, most prominently from adjacent pyramidal neurons in layer $\mathrm{V}$, but also from excitatory cells in upper cortical layers. To test the horizontal extent of the increase in the excitatory synaptic connectivity, we plotted the data along the horizontal direction, medial and lateral to the recorded cells. A two-way ANOVA analysis indicated that neurons in the undercut
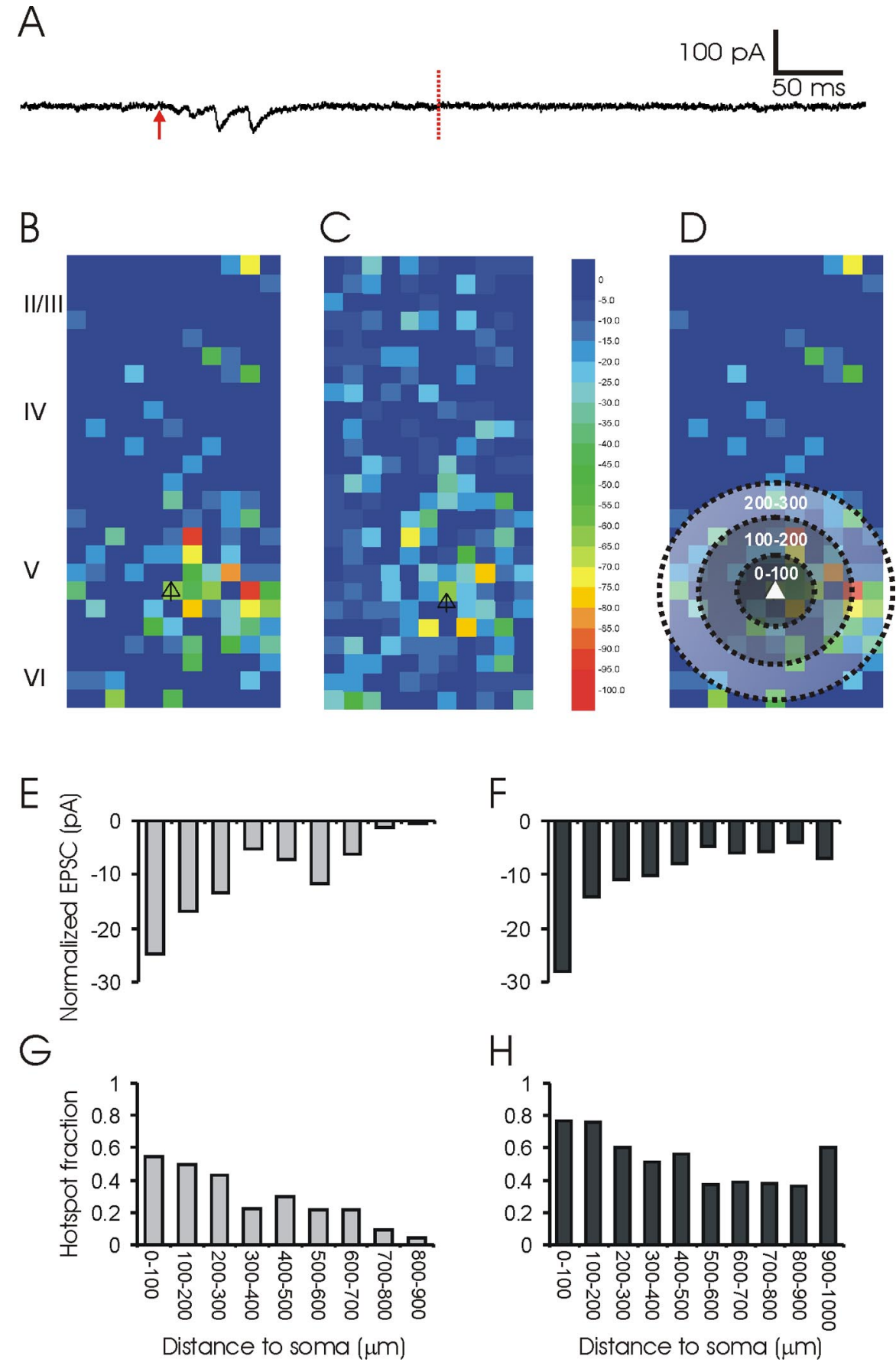

Figure 4. Representative maps and quantitative analysis of excitatory input to individual layer V pyramidal neurons in control $(\boldsymbol{B}, \boldsymbol{E}, \boldsymbol{G})$ and undercut cortex $(\boldsymbol{C}, \boldsymbol{F}, \boldsymbol{H}) . \boldsymbol{A}$, A representative trace showing an uncaged-glutamate-evoked EPSC in the absence of direct activation in a slice of control neocortex. The red arrow indicates the time of glutamate uncaging (200 $\mu$ s UV laser flash); the vertical dashed line indicates $200 \mathrm{~ms}$ after photostimulation. B, C, Maps of $500 \times 1200 \mu \mathrm{m}$ photostimulation grids showing the composite amplitude (see Materials and Methods) of EPSCs detected between 12 and 200 ms of uncaging stimulus onset. Both neurons received most of their excitatory inputs from layer $V$, and less from other layers. Scale next to $\boldsymbol{B}$, Composite amplitude of trigged events (in picoamperes; same for all of the following maps). D, Modified Sholl analysis was performed by calculating region-normalized EPSC amplitude (see Materials and Methods) or fraction of hot spots in concentric rings centered on the soma $(0 \mu \mathrm{m}$; white triangle) at distances of $100 \mu \mathrm{m}(0-100,100-200,200-300 \mu \mathrm{m}$, etc.). $\boldsymbol{E}, \boldsymbol{F}$, Plots of the region-normalized EPSC amplitude for EPSCs at different distances from the soma. $\mathbf{G}, \boldsymbol{H}$, Mean fraction of hot spots (from which EPSCs were evoked)/total spots at various distances from the soma.

cortex had a higher region-normalized EPSC amplitude and a greater fraction of hot spots $(F=22.6, p<0.0001$; and $F=42.0$, $p<0.0001$, respectively; two-way ANOVA) (Fig. 6C,D). Compared with controls, neurons in the undercut cortex had a higher 


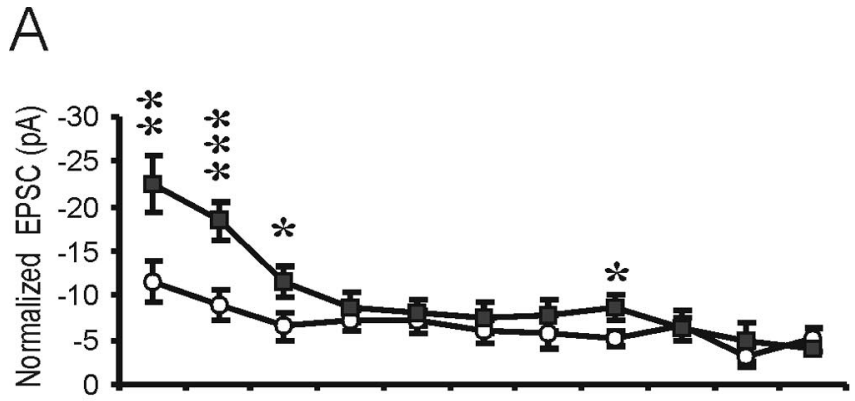

B

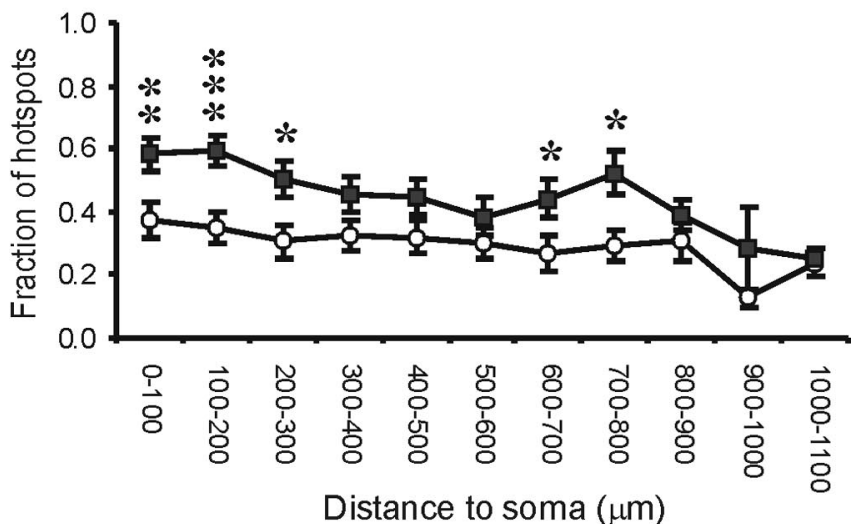

C

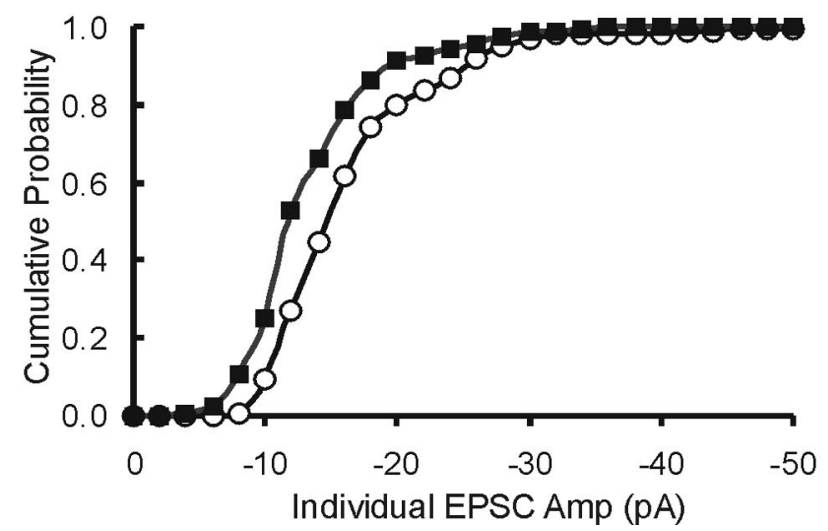

Figure 5. Enhanced excitatory synaptic input in layer V pyramidal neurons of undercut. $\boldsymbol{A}$, Modified Sholl analysis of region-normalized EPSC amplitude evoked by stimuli in $100 \mu \mathrm{m}$ bands at various distances from soma. Two-way ANOVA analysis showed a highly significant difference in region-normalized EPSC amplitude between the control and undercut group $(F=$ $9.0 ; p=0.003)$. There were significant increases in region-normalized EPSC amplitude evoked by stimuli in the area within a $300 \mu \mathrm{m}$ radius of the soma, and also in the $100 \mu \mathrm{m}$ circular band extending between 700 and $800 \mu \mathrm{m}$ from the soma. Black squares, Undercut; open circles, control in this and subsequent figures. $\boldsymbol{B}$, Modified Sholl analysis of mean fraction of hot spots at various distances from soma. Two-way ANOVA analysis indicated a significant difference in fractions of hot spots between the control and undercut groups $(F=28.2 ; p<0.0001)$. The increases in the fraction of hot spots at different distances were similar to the changes in region-normalized EPSC amplitude, except that the fraction also increased in the $100 \mu \mathrm{m}$ circular band at $600-700$ and $700-800 \mu \mathrm{m}$ radius from somata. Error bars indicate SEM. C, Cumulative histogram of mean individual EPSC amplitude showing leftward shift and decrease in mean individual EPSC amplitudes in undercut group (K-S test, $p<0.0001$ ). Data were obtained from 18 control neurons and 17 undercut neurons for Figures 5 and $6 .{ }^{*} p<0.05$; ${ }^{* *} p<0.01 ;{ }^{* * *} p<0.005$, in this and subsequent figures (Student's $t$ test).
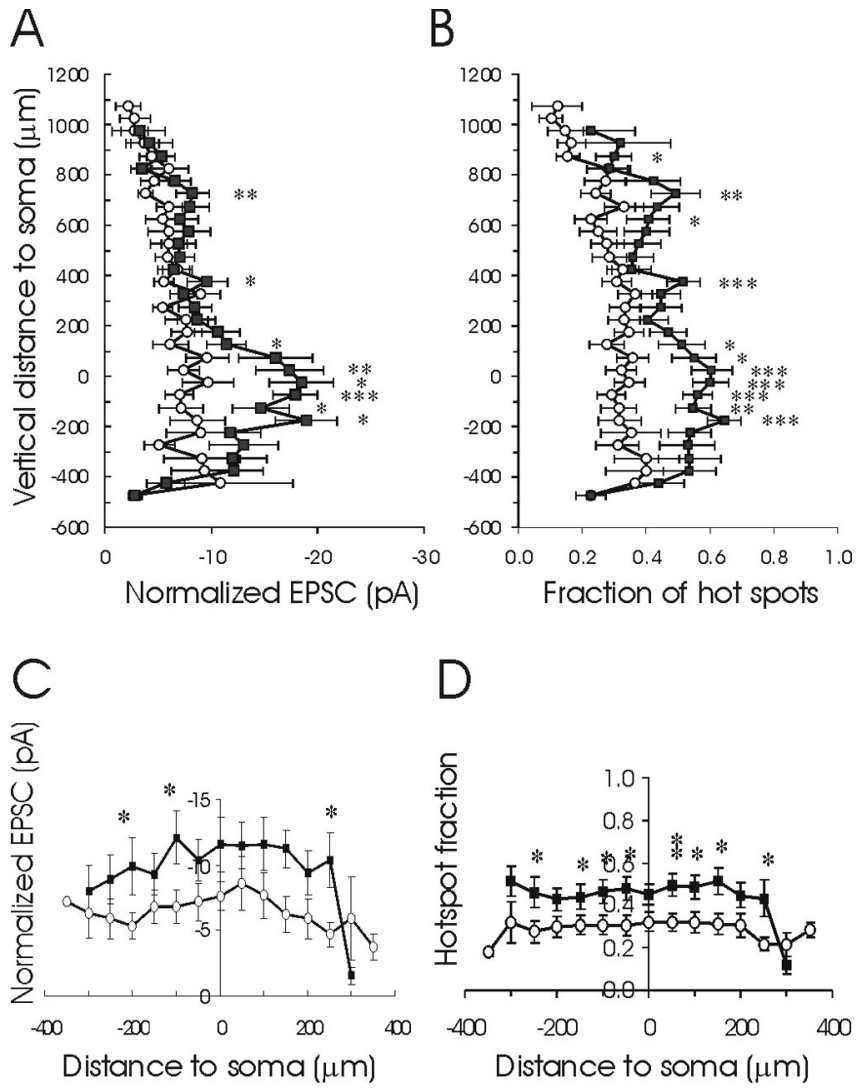

Figure 6. Layer-specific enhancement of excitatory synaptic input onto layer V pyramidal neurons. Two-way ANOVAs indicated highly significant effect ( $p<0.0001$ for all) of undercut lesion on the region-normalized EPSC amplitude $(A, C)$ and mean fraction of hot spots/total uncaging spots $(\boldsymbol{B}, \boldsymbol{D})$ at various vertical and horizontal distances from somata. $\boldsymbol{A}$, Comparison of region-normalized EPSC amplitude evoked by uncaging stimuli at various cortical depths. 0 , Depth of somata; positive along $y$-axis, toward pial surface; negative toward white matter in $\boldsymbol{A}$ and $\boldsymbol{B}$. Most significant increases in the region-normalized EPSC amplitude were between $-175 \mu \mathrm{m}$ below and $125 \mu \mathrm{m}$ above the somata in layer $\mathrm{V}$. A significant increase was also present at $375 \mu \mathrm{m}$ (approximately in layer IV) and $725 \mu \mathrm{m}$ (approximately in layers II/III). $\boldsymbol{B}$, Comparison of the mean fraction of hot spots/total uncaging spots at various vertical distances from soma. Significant increases in the undercut group were predominantly centered around layer V, consistent with the changes in region-normalized EPSC amplitude in $\boldsymbol{A}$ but were also present in more superficial laminas. C, Plot of region-normalized EPSC amplitude evoked by uncaging stimuli in layer $V$ at various horizontal distances from somata. Significant increases were present at several horizontal distances from the somata. Amplitude differences were not related to the position of the laser spots in relation to the transcortical cut ( $p>0.05$, two-way ANOVA). $x$-axis positive and negative, Lateral and medial to somata, respectively. $\boldsymbol{D}$, Relatively uniform changes in mean fraction of hot spots/total spots at various horizontal distances from somata in undercut versus control slices. Error bars indicate SEM.

region-normalized EPSC amplitude from laser uncaging at distances of 100 and $200 \mu \mathrm{m}$ medial and $250 \mu \mathrm{m}$ lateral to the somata ( $p<0.05$, Student's $t$ test) (Fig. $6 C$ ), as well as a greater fraction of hot spots at distances of $50-150$ and $250 \mu \mathrm{m}$ medial, and 50-150 and $250 \mu \mathrm{m}$ lateral to the somata $(p<0.05 \sim p<$ 0.01 , Student's $t$ test) (Fig. 6D). Two-way ANOVA analysis further indicated that there were no significant differences in either region-normalized EPSC amplitude or fraction of hot spots relative to the proximity of uncaging sites to the transcortical lesion, which was clearly visible in the slice.

\section{Discussion}

Reorganization of cortical connectivity consequent to injury is regarded as a key mechanism in epileptogenesis (see references above). Resulting small changes in the degree of recurrent exci- 
tation or inhibition in cortical circuits can lead to the emergence of epileptiform activity (Traub and Wong, 1982; Chagnac-Amitai and Connors, 1989). We used scanning laser photostimulation and whole-cell recording to determine whether the axonal sprouting of layer $\mathrm{V}$ pyramidal neurons in the partial neocortical isolation model of posttraumatic epileptogenesis (Salin et al., 1995 ) is associated with enhanced functional excitatory connectivity. Results indicate that layer $\mathrm{V}$ pyramidal cells in the injured cortex receive an excitatory synaptic input that is increased in spatial extent and intensity and is derived principally from presynaptic neurons in layer V. The increased number of EPSCs evoked by each stimulus in the undercut cortex is balanced by the decreased amplitude of individual events, so that the composite EPSC is similar in amplitude in control and injured cortex. However, it is likely that repetitive EPSCs would translate into a larger $\mathrm{AP}$ output by layer $\mathrm{V}$ pyramidal neurons in vivo, where resting potential is significantly more depolarized (Destexhe and Pare, 1999).

\section{Laser-scanning photostimulation for analysis of circuit reorganization}

The combination of UV photostimulation and whole-cell recordings has been used effectively in studies of hippocampal (Molnar and Nadler, 1999; Shao and Dudek, 2004) and neocortical connectivity (Callaway and Katz, 1993; Katz and Dalva, 1994; Kotter et al., 1998; Staiger et al., 2000; Schubert et al., 2001; Callaway, 2002; Dodt et al., 2003; and others). The technique is highly efficient for mapping details of interlaminar and intercolumnar connections in neocortex (Callaway, 2002; Dodt et al., 2003; Shepherd et al., 2003; Shepherd and Svoboda, 2005) and has been applied to demonstrate enhanced connectivity among both CA1 pyramidal neurons and dentate granule cells in models of temporal lobe epilepsy (Molnar and Nadler, 1999; Shao and Dudek, 2004). The advantages and potential limitations have been discussed previously (Shepherd and Svoboda, 2005, and references therein); however, additional issues arise when lesioned and control cortex are to be compared. The density of surviving neurons, their intrinsic excitability, presynaptic terminal and receptor functions, and other factors, such as the efficiency of clearance of released glutamate, may each be altered in the injured cortex, potentially affecting the numbers of cells responding to the uncaging stimulus, the size of the evoked EPSCs, and the resulting maps. Furthermore, responses to injury can vary over time (Fishman and Mattu, 1993; Marchenko et al., 2004), and the current study focused on only one time point. The experiments that demonstrated sprouting in the partially isolated cortex were also done at $\sim 2-3$ weeks after injury, but sprouting may be a dynamic process (Marchenko et al., 2004) so that different results might be obtained if mapping were applied earlier or later after injury. Some of these variables have been considered (Fig. 2), but others that may have contributed to the differences between control and partially isolated cortex are yet to be examined.

\section{Enhanced excitation}

The hypothesis that there is increased functional excitatory connectivity within the partially isolated cortex is supported by the increased density of hot spots (Figs. $5 B, 6 B, D$ ), and an increase in the region-normalized EPSC amplitude that results from both the increase in hot spots and an increased incidence of multipeaked flash-evoked EPSCs in these neurons (Figs. 5A, 6A, C). The lack of significant increase in sEPSC frequency and decreased amplitude of sEPSC and single evoked EPSCs in the undercut cortex were unexpected, as previous results indicated that the frequency and amplitude of sEPSCs, and the input-output slope of evoked EPSCs were increased (Li and Prince, 2002). The reasons for this discrepancy may lie in the different experimental conditions in the two series of experiments, including the low temperature and elevated divalent cation concentration in the current study that could have had differential effects on excitatory synaptic transmission in the injured cortex. The sEPSC frequencies recorded in the current study at room temperature $\left(\sim 23^{\circ} \mathrm{C} ; 2.7 \pm 0.3 \mathrm{~Hz}\right.$ in control and $3.2 \pm 0.7 \mathrm{~Hz}$ in undercut) were lower than those reported in an previous study in which recordings were made at $32^{\circ} \mathrm{C}(7.4 \pm 0.6$ in control and $9.3 \pm 0.7$ in undercut) ( $\mathrm{Li}$ and Prince, 2002). Thus, in both studies, there is a trend toward increased frequency of sEPSCs in undercut cortex, but the previous study did demonstrate an increase in sEPSC amplitude that was not reproduced here. A potential explanation for smaller EPSC amplitude in our current study would be that the newly sprouted connections are made selectively onto distal dendritic regions from which the EPSCs would be subjected to significant electrotonic filtering and thus be of smaller apparent magnitude. This result would be consistent with a slowed rise time, as expected for electrotonic filtering; however, it was not possible to reliably resolve rise times in the multipeaked composite responses evoked by the uncaging stimuli. Resolution of this issue will require additional study.

Because the mean composite EPSC amplitude in our mapping experiments is a summation of all EPSCs evoked from a given presynaptic spot, the postsynaptic response would be affected by the number of neurons being activated, the number of APs fired per stimulated neuron, the total number of synaptic contacts between presynaptic and postsynaptic neurons, the site(s) of synaptic contacts, the release probability at presynaptic terminals, and the density and structure of postsynaptic receptors (Shepherd and Svoboda, 2005). Under our experimental conditions, contamination of results by unrecognized polysynaptic responses evoked by stimulation of epileptogenic cortex (Prince and Tseng, 1993 ) would be unlikely (see Materials and Methods). Also, increased intrinsic excitability known to occur in pyramidal neurons of partially isolated cortex (Prince and Tseng, 1993; Jin et al., 2005a), did not affect the number of APs induced by direct glutamate-induced depolarization (Fig. 2), making enhanced presynaptic excitability an unlikely cause for the increase in multipeaked EPSCs. The multipeaked EPSCs likely reflect events evoked by release of glutamate from the synaptic terminals of several neurons in the area of the hot spot. The increased incidence of multipeaked EPSCs would then be attributable to either a greater number of activated neurons, or increased connectivity from activated cells onto the recorded neuron. In light of the known decrease in density of pyramidal cells in the partially insolated cortex (Prince and Tseng, 1993; Graber et al., 1999), and anatomical results showing axonal sprouting (Salin et al., 1995), the latter possibility appears most likely. The distribution of hot spots in our experiments (Fig. 6B) is consistent with the anatomical data showing that sprouting is most prominent within layer $\mathrm{V}$, the lamina in which interictal epileptiform events originate (Prince and Tseng, 1993; Hoffman et al., 1994). The increase in the fraction of sites from which EPSCs are evoked strongly suggests the formation of new synapses that make a major contribution to the stronger and spatially more extensive functional excitatory connections between layer $\mathrm{V}$ pyramidal neurons. Because dendritic trees of layer $\mathrm{V}$ pyramidal neurons do not undergo outgrowth after undercut lesion (Salin et al., 1995) and there is no increase in the number of evoked APs of layer V cells when stim- 
ulated in the upper layer (Fig. 2D), it is likely that axonal sprouting and formation of new synapses in excitatory neurons of more superficial layers also contribute to the significant increases in region-normalized EPSC amplitude and fraction of hot spots in upper cortical layers (Fig. 6A,B).

\section{Functional implications}

Our results demonstrate significant increases in functional excitatory connectivity onto layer $\mathrm{V}$ pyramidal neurons of undercut cortex, thus supporting the hypothesis that the axonal sprouting found in anatomical experiments (Salin et al., 1995; Marchenko et al., 2004) enhances cortical excitability in this model of posttraumatic epileptogenesis. The spatial distribution of anatomical sprouting and altered uncaging responses of presynaptic cells in layer $\mathrm{V}$ is consistent with the origin of interictal epileptiform activity in that lamina (Hoffman et al., 1994). The new recurrent excitatory connections between layer $\mathrm{V}$ pyramidal neurons likely result in enhanced synchronization within the cortical network and contribute to the generation of epileptiform activity in the undercut animals both in vitro and in vivo (for review, see Graber and Prince, 2006). Extensive synaptic reorganization and resulting enhanced excitatory connectivity is also a key mechanism underlying epileptogenesis in temporal lobe epilepsy (Wong et al., 1984; Perez et al., 1996; Wuarin and Dudek, 1996; Sutula et al., 1998; Zhang and Houser, 1999; Wenzel et al., 2000; Lehmann et al., 2001; Buckmaster et al., 2002; Smith and Dudek, 2002). Other factors, such as less effective GABAergic postsynaptic inhibition attributable to a variety of mechanisms (Ribak et al., 1982; Rice et al., 1996; Buckmaster and Jongen-Relo, 1999; Kobayashi et al., 2003), although not evident here, would work hand-in-hand with enhanced recurrent excitation to promote seizures (Traub and Wong, 1982).

Axonal sprouting is likely a ubiquitous response to cortical injury (Maxwell et al., 1990; Fishman and Mattu, 1993), and yet posttraumatic epilepsy occurs infrequently (Annegers et al., 1980), emphasizing the multifactorial nature of epileptogenesis. Our results show that this regenerative process results in functionally stronger and spatially expanded cortical connections that may constitute a substrate for functional recovery after neuronal injuries (Carmichael et al., 2001; Ramirez, 2001; Chuckowree et al., 2004) as well as a mechanism underlying epileptogenesis.

\section{References}

Annegers JF, Grabow JD, Groover RV, Laws Jr ER, Elveback LR, Kurland LT (1980) Seizures after head trauma: a population study. Neurology 30:683-689.

Bacci A, Rudolph U, Huguenard JR, Prince DA (2003) Major differences in inhibitory synaptic transmission onto two neocortical interneuron subclasses. J Neurosci 23:9664-9674.

Bernard C, Esclapez M, Hirsch JC, Ben-Ari Y (1998) Interneurons are not so dormant in temporal lobe epilepsy: a critical reappraisal of the dormant basket cell hypothesis. Epilepsy Res 32:93-103.

Buckmaster PS, Jongen-Relo AL (1999) Highly specific neuron loss preserves lateral inhibitory circuits in the dentate gyrus of kainate-induced epileptic rats. J Neurosci 19:9519-9529.

Buckmaster PS, Zhang GF, Yamawaki R (2002) Axon sprouting in a model of temporal lobe epilepsy creates a predominantly excitatory feedback circuit. J Neurosci 22:6650-6658.

Callaway EM (2002) Cell type specificity of local cortical connections. J Neurocytol 31:231-237.

Callaway EM, Katz LC (1993) Photostimulation using caged glutamate reveals functional circuitry in living brain slices. Proc Natl Acad Sci USA 90:7661-7665.

Carmichael ST (2003) Plasticity of cortical projections after stroke. Neuroscientist 9:64-75.

Carmichael ST, Wei L, Rovainen CM, Woolsey TA (2001) New patterns of intra-cortical projections after focal cortical stroke. Neurobiol Dis 8:910-922.

Chagnac-Amitai Y, Connors BW (1989) Horizontal spread of synchronized activity in neocortex and its control by GABA-mediated inhibition. J Neurophysiol 61:747-758.

Chuckowree JA, Dickson TC, Vickers JC (2004) Intrinsic regenerative ability of mature CNS neurons. Neuroscientist 10:280-285.

Cossart R, Bernard C, Ben Ari Y (2005) Multiple facets of GABAergic neurons and synapses: multiple fates of GABA signalling in epilepsies. Trends Neurosci 28:108-115.

Dantzker JL, Callaway EM (2000) Laminar sources of synaptic input to cortical inhibitory interneurons and pyramidal neurons. Nat Neurosci 3:701-707.

Destexhe A, Pare D (1999) Impact of network activity on the integrative properties of neocortical pyramidal neurons in vivo. J Neurophysiol 81:1531-1547.

Dodt HU, Schierloh A, Eder M, Zieglgansberger W (2003) Circuitry of rat barrel cortex investigated by infrared-guided laser stimulation. NeuroReport 14:623-627.

Dudek FE, Spitz M (1997) Hypothetical mechanisms for the cellular and neurophysiologic basis of secondary epileptogenesis: proposed role of synaptic reorganization. J Clin Neurophysiol 14:90-101.

Esclapez M, Hirsch JC, Ben-Ari Y, Bernard C (1999) Newly formed excitatory pathways provide a substrate for hyperexcitability in experimental temporal lobe epilepsy. J Comp Neurol 408:449-460.

Fishman PS, Mattu A (1993) Fate of severed cortical projection axons. J Neurotrauma 10:457-470.

Franck JE, Kunkel DD, Baskin DG, Schwartzkroin PA (1988) Inhibition in kainate-lesioned hyperexcitable hippocampi: physiologic, autoradiographic and immunocytochemical observations. J Neurosci 8:1991-2002.

Golarai G, Greenwood AC, Feeney DM, Connor JA (2001) Physiological and structural evidence for hippocampal involvement in persistent seizure susceptibility after traumatic brain injury. J Neurosci 21:8523-8537.

Graber KD, Prince DA (1999) Tetrodotoxin prevents posttraumatic epileptogenesis in rats. Ann Neurol 46:234-242.

Graber KD, Prince DA (2006) Chronic partial cortical isolation. In: Models of seizures and epilepsy (Pitkanen A, Schwartzkroin P, Moshe S, eds), pp 477-493. San Diego: Elsevier.

Graber KD, Kharazia VN, Parada I, Prince DA (1999) Parvalbumin containing interneurons are spared in the undercut model of posttraumatic epileptogenesis. Epilepsia 40 [Suppl 7]:31.

Hoffman SN, Salin PA, Prince DA (1994) Chronic neocortical epileptogenesis in vitro. J Neurophysiol 71:1762-1773.

Horikawa K, Armstrong WE (1988) A versatile means of intracellular labeling: injection of biocytin and its detection with avidin conjugates. J Neurosci Methods 25:1-11.

Jin X, Huguenard JR, Prince DA (2005a) Impaired $\mathrm{Cl}^{-}$extrusion in layer V pyramidal neurons of chronically injured epileptogenic neocortex. J Neurophysiol 93:2117-2126.

Jin X, Huguenard JR, Prince DA (2005b) Increased layer V excitatory connectivity in the neocortical undercut model of post-traumatic epilepsy. Epilepsia 46 [Suppl 8]:109.

Katz LC, Dalva MB (1994) Scanning laser photostimulation: a new approach for analyzing brain circuits. J Neurosci Methods 54:205-218.

Kittelberger JM, Mooney R (1999) Lesions of an avian forebrain nucleus that disrupt song development alter synaptic connectivity and transmission in the vocal premotor pathway. J Neurosci 19:9385-9398.

Kobayashi M, Wen X, Buckmaster PS (2003) Reduced inhibition and increased output of layer II neurons in the medial entorhinal cortex in a model of temporal lobe epilepsy. J Neurosci 23:8471-8479.

Kotter R, Staiger JF, Zilles K, Luhmann HJ (1998) Analyzing functional connectivity in brain slices by a combination of infrared video microscopy, flash photolysis of caged compounds and scanning methods. Neuroscience 86:265-277.

Kotti T, Riekkinen PJ, Miettinen R (1997) Characterization of target cells for aberrant mossy fiber collaterals in the dentate gyrus of epileptic rat. Exp Neurol 146:323-330.

Lee JK, Kim JE, Sivula M, Strittmatter SM (2004) Nogo receptor antagonism promotes stroke recovery by enhancing axonal plasticity. J Neurosci 24:6209-6217.

Lehmann TN, Gabriel S, Eilers A, Njunting M, Kovacs R, Schulze K, Lanksch WR, Heinemann U (2001) Fluorescent tracer in pilocarpine-treated rats 
shows widespread aberrant hippocampal neuronal connectivity. Eur J Neurosci 14:83-95.

Li H, Prince DA (2002) Synaptic activity in chronically injured, epileptogenic sensory-motor neocortex. J Neurophysiol 88:2-12.

Longo BM, Mello LE (1997) Blockade of pilocarpine- or kainate-induced mossy fiber sprouting by cycloheximide does not prevent subsequent epileptogenesis in rats. Neurosci Lett 226:163-166.

Lynch M, Sutula T (2000) Recurrent excitatory connectivity in the dentate gyrus of kindled and kainic acid-treated rats. J Neurophysiol 83:693-704.

Marchenko VG, Pasikova NV, Kositsyn NS (2004) Intracortical synchronization of epileptic discharges at different stages of ultrastructural rearrangements in a completely neuronally isolated area of rat neocortex. Neurosci Behav Physiol 34:307-313.

Markram H, Lubke J, Frotscher M, Roth A, Sakmann B (1997) Physiology and anatomy of synaptic connections between thick tufted pyramidal neurones in the developing rat neocortex. J Physiol (Lond) 500:409-440.

Maxwell WL, Follows R, Ashhurst DE, Berry M (1990) The response of the cerebral hemisphere of the rat to injury. I. The mature rat. Philos Trans $\mathrm{R}$ Soc Lond B Biol Sci 328:479-500.

McKinney RA, Debanne D, Gahwiler BH, Thompson SM (1997) Lesioninduced axonal sprouting and hyperexcitability in the hippocampus in vitro: implications for the genesis of posttraumatic epilepsy. Nat Med 3:990-996.

Molnar P, Nadler JV (1999) Mossy fiber-granule cell synapses in the normal and epileptic rat dentate gyrus studied with minimal laser photostimulation. J Neurophysiol 82:1883-1894.

Nadler JV (2003) The recurrent mossy fiber pathway of the epileptic brain. Neurochem Res 28:1649-1658.

Okazaki MM, Molnar P, Nadler JV (1999) Recurrent mossy fiber pathway in rat dentate gyrus: synaptic currents evoked in the presence and absence of seizure-induced growth. J Neurophysiol 81:1645-1660.

Patrylo PR, Dudek FE (1998) Physiological unmasking of new glutamatergic pathways in the dentate gyrus of hippocampal slices from kainateinduced epileptic rats. J Neurophysiol 79:418-429.

Perez Y, Morin F, Beaulieu C, Lacaille J-C (1996) Axonal sprouting of CA1 pryamidal cells in hyperexcitable hippocampal slices of kainate-treated rats. Eur J Neurosci 8:736-748.

Prince DA (1999) Epileptogenic neurons and circuits. Adv Neurol 79:665-684.

Prince DA, Tseng GF (1993) Epileptogenesis in chronically injured cortex: in vitro studies. J Neurophysiol 69:1276-1291.

Prince DA, Salin P, Tseng GF, Hoffman S, Parada I (1997) Axonal sprouting and epileptogenesis. Adv Neurol 72:1-8.

Purpura DP, Housepian EM (1961) Morphological and physiological properties of chronically isolated immature neocortex. Exp Neurol 4:377-401.

Ramirez JJ (2001) The role of axonal sprouting in functional reorganization after CNS injury: lessons from the hippocampal formation. Restor Neurol Neurosci 19:237-262.

Ribak CE, Harris AB, Vaughn JE, Roberts E (1979) Inhibitory, GABAergic nerve terminals decrease at sites of focal epilepsy. Science 205:211-214.

Ribak CE, Bradurne RM, Harris AB (1982) A preferential loss of GABAergic, symmetric synapses in epileptic foci: a quantitative ultrastructural analysis of monkey neocortex. J Neurosci 2:1725-1735.

Rice A, Rafiq A, Shapiro SM, Jakoi ER, Coulter DA, Delorenzo RJ (1996) Long-lasting reduction of inhibitory function and $\gamma$-aminobutyric acid type A receptor subunit mRNA expression in a model of temporal lobe epilepsy. Proc Natl Acad Sci USA 93:9665-9669.

Salin P, Tseng G-F, Salin P, Hoffman S, Parada I, Prince DA (1995) Axonal sprouting in layer $\mathrm{V}$ pyramidal neurons of chronically injured cerebral cortex. J Neurosci 15:8234-8245.

Santhakumar V, Ratzliff AD, Jeng J, Toth K, Soltesz I (2001) Long-term hyperexcitability in the hippocampus after experimental head trauma. Ann Neurol 50:708-717.

Scharfman HE, Sollas AL, Berger RE, Goodman JH (2003) Electrophysiological evidence of monosynaptic excitatory transmission between granule cells after seizure-induced mossy fiber sprouting. J Neurophysiol 90:2536-2547.

Schubert D, Staiger JF, Cho N, Kötter R, Zilles K, Luhmann HJ (2001)
Layer-specific intracolumnar and transcolumnar functional connectivity of layer V pyramidal cells in rat barrel cortex. J Neurosci 21:3580-3592.

Shao LR, Dudek FE (2004) Increased excitatory synaptic activity and local connectivity of hippocampal CA1 pyramidal cells in rats with kainateinduced epilepsy. J Neurophysiol 92:1366-1373.

Shepherd GMG, Svoboda K (2005) Laminar and columnar organization of ascending excitatory projections to layer $2 / 3$ pyramidal neurons in rat barrel cortex. J Neurosci 25:5670-5679.

Shepherd GMG, Pologruto TA, Svoboda K (2003) Circuit analysis of experience-dependent plasticity in the developing rat barrel cortex. Neuron 38:277-289.

Sloviter RS (1987) Decreased hippocampal inhibition and a selective loss of interneurons in experimental epilepsy. Science 235:73-76.

Sloviter RS (1992) Possible functional consequences of synaptic reorganization in the dentate gyrus of kainate-treated rats. Neurosci Lett 137:91-96.

Smith BN, Dudek FE (2002) Network interactions mediated by new excitatory connections between CA1 pyramidal cells in rats with kainiteinduced epilepsy. J Neurophysiol 87:1655-1658.

Staiger JF, Kotter R, Zilles K, Luhmann HJ (2000) Laminar characteristics of functional connectivity in rat barrel cortex revealed by stimulation with caged-glutamate. Neurosci Res 37:49-58.

Stroemer RP, Kent TA, Hulsebosch CE (1998) Enhanced neocortical neural sprouting, synaptogenesis, and behavioral recovery with D-Amphetamine therapy after neocortical infarction in rats. Stroke 29:2381-2395.

Sutula T, Zhang P, Lynch M, Sayin U, Golarai G, Rod R (1998) Synaptic and axonal remodeling of mossy fibers in the hilus and supragranular region of the dentate gyrus in kainate-treated rats. J Comp Neurol 390:578 -594.

Sutula TP, Golarai G, Cavazos J (1992) Assessing the functional significance of mossy fiber sprouting. Epilepsy Res Suppl 7:251-259.

Tauck DL, Nadler JV (1985) Evidence of functional mossy fiber sprouting in hippocampal formation of kainic acid treated rats. J Neurosci 5:1016-1022.

Traub RD, Wong RK (1982) Cellular mechanism of neuronal synchronization in epilepsy. Science 216:745-747.

Tsai PS, Nishimura N, Yoder EJ, White A, Dolnick E, Kleinfeld D (2002) Principles, design and construction of a two photon scanning microscope for in vitro and in vivo studies. In: Methods for in vivo optical imaging (Frostig R, ed), pp 113-171. Boca Raton, FL: CRC.

Tseng GF, Prince DA (1996) Structural and functional alterations in rat corticospinal neurons after axotomy. J Neurophysiol 75:248-267.

Tseng GF, Parada I, Prince DA (1991) Double-labelling with rhodamine beads and biocytin: a technique for studying corticospinal and other projection neurons in vitro. J Neurosci Methods 37:121-131.

Ulrich D, Huguenard JR (1996) $\mathrm{GABA}_{\mathrm{B}}$ receptor-mediated responses in GABAergic projection neurones of rat nucleus reticularis thalami in vitro. J Physiol (Lond) 493:845-854.

Wei DS, Mei YA, Bagal A, Kao JPY, Thompson SM, Tang CM (2001) Compartmentalized and binary behavior of terminal dendrites in hippocampal pyramidal neurons. Science 293:2272-2275.

Wenzel HJ, Woolley CS, Robbins CA, Schwartzkroin PA (2000) Kainic acid-induced mossy fiber sprouting and synapse formation in the dentate gyrus of rats. Hippocampus 10:244-260.

Wong RK, Miles R, Traub RD (1984) Local circuit interactions in synchronization of cortical neurones. J Exp Biol 112:169-178.

Wuarin JP, Dudek FE (1996) Electrographic seizures and new recurrent excitatory circuits in the dentate gyrus of hippocampal slices from kainatetreated epileptic rats. J Neurosci 16:4438-4448.

Wuarin JP, Dudek FE (2001) Excitatory synaptic input to granule cells increases with time after kainate treatment. J Neurophysiol 85:1067-1077.

Xiang Z, Huguenard JR, Prince DA (2002) Synaptic inhibition of pyramidal cells evoked by different interneuronal subtypes in layer $\mathrm{V}$ of rat visual cortex. J Neurophysiol 88:740-750.

Zhang N, Houser CR (1999) Ultrastructural localization of dynorphin in the dentate gyrus in human temporal lobe epilepsy: a study of reorganized mossy fiber synapses. J Comp Neurol 405:472-490.

Zhu WJ, Roper SN (2000) Reduced inhibition in an animal model of cortical dysplasia. J Neurosci 20:8925-8931. 